ISSN 1808-3765

\title{
POTENCIAL HÍDRICO FOLIAR DA MELANCIEIRA EM RESPOSTA A VARIAÇÃO NO CONTEÚDO DE ÁGUA NO SOLO
}

\section{EDILSON RAMOS GOMES ${ }^{1}$; LÍGIA RENATA ALMEIDA DA SILVA ${ }^{2}$; ADERSON SOARES DE ANDRADE JÚNIOR ${ }^{3}$; VALDEMICIO FERREIRA DE SOUSA ${ }^{4}$ E FRANCISCO EDINALDO PINTO MOUSINHO}

\footnotetext{
${ }^{1}$ Doutorando em Agronomia (Irrigação e Drenagem), Universidade Estadual Paulista “Júlio de Mesquita Filho", Campos Botucatu-SP. e-mail: edilsonevj@hotmail.com

${ }^{2}$ Doutoranda em Genética e Melhoramento da Universidade Estadual do Norte Fluminense/UENF-RJ.

${ }^{3}$ Doutor, Pesquisador da Embrapa Meio-Norte, Teresina-PI.

${ }^{4}$ Doutor, Pesquisador da Embrapa Cocais e Bolsista PQ do CNPq, São Luis-MA.

${ }^{5}$ Prof. Doutor, Departamento de Engenharia Agrícola e Solos, UFPI, Teresina-PI.
}

\section{RESUMO}

O objetivo deste trabalho foi avaliar o potencial hídrico foliar da melancieira em resposta a variação do conteúdo de água no solo, com a aplicação de diferentes lâminas de irrigação nas condições de solo e clima do Piauí. O ensaio foi realizado no campo experimental da Embrapa Meio-Norte, onde utilizou-se um delineamento em blocos casualizados, com cinco tratamentos (lâminas de irrigação com base na evapotranspiração de referência - ETo): 50\%; $75 \% ; 100 \% ; 125 \%$ e $150 \%$, com quatro repetições. A cultivar avaliada foi a Crimson Sweet. $\mathrm{O}$ estado da água no solo foi medido com o auxílio de uma sonda de capacitância, com leituras nas profundidades de $0,10 \mathrm{~m} ; 0,20 \mathrm{~m} ; 0,30 \mathrm{~m}$ e $0,40 \mathrm{~m}$. O potencial hídrico foliar $\left(\Psi_{\mathrm{F}}\right)$ foi medido por meio de uma bomba de pressão tipo Scholander, as medições foram realizadas no período da manhã considerando os estágios de desenvolvimento da cultura (vegetativo, floração e frutificação). O potencial hídrico foliar $\left(\Psi_{\mathrm{F}}\right)$ da melancieira foi influenciado pelo perfil de distribuição da umidade no solo em função das lâminas de irrigação. Os teores de umidade do solo tendem a reduzir à medida que aumentou a profundidade no perfil do solo. Foram registrados os maiores potenciais hídricos foliares nos estágios de florescimento e frutificação da cultura.

PALAVRAS CHAVES: Citrullus lanatus, Potencial hídrico foliar, manejo de irrigação.

\section{INTRODUÇÃO}

As cucurbitáceas têm uma grande importância econômica, sendo cultivada em todo o mundo. Segundo a FAO (2013), a produção mundial em 2011 foi de 102.889.076 toneladas, sendo os maiores produtores a China, Turquia, Irã, Brasil e os Estados Unidos, que juntos respondem por mais de 77, 89\% da produção mundial. Em 2010, no Brasil, foram produzidos 2.052.928 toneladas de melancia, em 94.946 ha de área colhida, sendo a região nordeste responsável por uma porcentagem de 36,7 e 34,2 da área colhida e da produção, respectivamente (IBGE, 2010). Os estados do Rio Grande do Sul, São Paulo, Bahia e Goiás são os maiores produtores (AGRIANUAL, 2008). Dentre as plantas desta família, a melancia (Citrullus lanatus L.) é uma das espécies cultivada praticamente em quase todo o território nacional, onde encontrou boas condições ambientais para ótimo desenvolvimento e produtividade.

Costa e Leite (2002) descrevem como fatores favoráveis ao desenvolvimento da cultura e a qualidade dos frutos as condições de clima ameno a quente, dias longos e de baixa umidade relativa, sendo de 23 a $28^{\circ} \mathrm{C}$ a faixa ótima de temperatura para uma boa produção. 
O estado do Piauí apresenta em geral condições de solo e clima favorável ao desenvolvimento dessa cultura, podendo tornar-se um significativo produtor sob regime de irrigação. No entanto, a escassez de água aliada a problemas de salinidade são dois fatores limitantes ao rendimento da cultura, reduzindo a eficiência do sistema agrícola, necessitando, então, de um manejo de irrigação que atenda às necessidades das culturas, proporcionando condições satisfatórias para a obtenção de um bom rendimento.

A exigência de água durante o ciclo de 100 dias da cultura da melancieira varia de 400 a $600 \mathrm{~mm}$ (Andrade et al., 2013), dependendo das condições climáticas, da duração do ciclo e do sistema de irrigação. A cultura apresenta um consumo de água diferenciado no decorrer do seu ciclo, cuja exigência aumenta do início da ramificação até a frutificação. A deficiência hídrica atrasa o crescimento da planta e diminui o tamanho dos frutos. Os estádios mais críticos são o florescimento e a formação da produção (crescimento de frutos), seguida do período de rápido desenvolvimento de ramas (Doorenbos e Kassam, 2000).

O déficit ou excesso hídrico reflete o estado da água na planta que é uma propriedade afetada pelo balanço entre a perda de vapor d'água pelas folhas para a atmosfera e a absorção da água pelas raízes, também pode ser caracterizado pelo potencial hídrico (Klar, 1984).

Desta forma o objetivo deste trabalho foi avaliar o efeito do potencial hídrico foliar da melancieira em resposta a variação no conteúdo de água no solo, em função da aplicação de diferentes lâminas de irrigação por gotejamento, sobre a produtividade de frutos, nas condições de solo e clima de Teresina-PI.

\section{MATERIAIS E MÉTODOS}

O experimento foi conduzido no Campo Experimental da Embrapa Meio-Norte, em Teresina-PI $\left(05^{\circ} 05^{\prime}\right.$ S; 42 $48^{\prime} \mathrm{W}$ e 74,4m). Segundo a classificação de Köeppen, o clima da cidade é do tipo Aw', ou seja, tropical quente e úmido, com período chuvoso do verão ao outono, com umidade relativa média anual de $75 \%$, temperatura média do ar de $28,6^{\circ} \mathrm{C}$ e a precipitação pluviométrica anual é de $1291 \mathrm{~mm}$ (BASTOS et al., 2007).

O solo foi classificado como um argissolo vermelho amarelo distrófico (EMBRAPA, 1999). As características químicas do solo foram obtidas através da realização de análise de fertilidade do solo, a partir de amostras deformadas de solo da área experimental, nas camadas de 0 a 0,20 e de 0,20 a $0,40 \mathrm{~m}$.

\section{Cultivar e práticas culturais}

O trabalho foi implantado com a cultura da melancia, especificamente a cultivar Crimson Sweet, com ciclo médio de 70 dias após transplantio. Após 12 dias da germinação $(01 / 09 / 2011)$ as mudas foram transplantadas para o campo, com espaçamento de 2,0 m entre fileiras e $1,0 \mathrm{~m}$ entre plantas.

A adubação foi toda via fertirrigação com bombas injetoras de fertilizante do tipo TMB, instaladas em cavaletes nas linhas de derivação, com aplicação diária. Os fertilizantes foram aplicadas a partir da marcha de absorção de nutrientes pela cultura da melancia (SOUSA et al., 1999). Os adubos utilizados foram: uréia $(\mathrm{N})$, cloreto de potássio (KCl), MAP, micronutrientes: ácido bórico $\left(\mathrm{H}_{3} \mathrm{BO}_{3}\right)$, oxido de zinco $(\mathrm{ZnO})$, oxido de cobre $(\mathrm{CuO})$, oxido de manganês $\left(\mathrm{MnO}_{2}\right)$, molibdato de sódio $\left(\mathrm{NaMO}_{2}\right)$ durante todo o ciclo da cultura. Para os tratos culturais foram realizados quatro capinas no decorrer do ciclo. Os controles fitossanitários foram realizados conforme as recomendações de Silva et al. (2007). 


\section{Sistema de irrigação}

A aplicação de água foi realizada por um sistema de irrigação por gotejamento, utilizando o tubo gotejador com espaçamento de $0,50 \mathrm{~m}$ entre gotejadores, com uma vazão de $1,65 \mathrm{~L} \mathrm{~h}^{-1}$ por gotejador e espaçamento de $2 \mathrm{~m}$ nas linhas laterais. O sistema de irrigação foi dividido em cinco setores e a irrigação de cada setor foi independente, cada um com seu cavalete, registro e hidrômetro. Posteriormente determinou-se os valores médios das lâminas de irrigação em cada parcela, utilizando-se as leituras nos hidrômetros. O sistema de irrigação por gotejamento foi escolhido devido à alta uniformidade de irrigação e precisão no controle da lâmina aplicada.

\section{Tratamentos e delineamento experimental}

O delineamento experimental utilizado foi em blocos casualizados, com cinco tratamentos e quatro repetições. Os tratamentos constaram de cinco lâminas de irrigação: $50 \% ; 75 \% ; 100 \% ; 125 \%$ e $150 \%$ da evapotranspiração de referência (ETo).

O manejo da irrigação foi realizado diariamente pelo método do balanço de água no solo, com base nos valores diários dos elementos climáticos (temperatura do ar, umidade relativa do ar, radiação solar), os quais foram obtidos da estação agrometeorológica automática (local). O valor da ETo foi calculado diariamente pelo modelo de PenmanMonteith (ALLEN et al., 1998).

Os dados foram submetidos à análise de variância, as médias foram comparadas pelo teste Tukey, a 5\% de significância, para avaliar os efeitos da lâminas aplicadas no potencial hídrico foliar e na umidade do solo em função da produtividade e da interação entre eles. Para a realização das análises utilizou-se o programa software SISVAR- Sistema para Análise de Variância, segundo Ferreira (2000).

\section{Monitoramentos da umidade no solo}

Os valores de conteúdo de água no perfil do solo (\% em volume) foram obtidos utilizando-se uma sonda de capacitância, modelo Diviner $2000^{\circledR}$. O princípio de funcionamento do equipamento é baseado na capacitância, ou seja, quando ativado, a matriz solo-água-ar forma o meio dielétrico do capacitor, este é conectado a um circuito oscilatório em que as trocas de frequência do circuito dependem das trocas de capacitância.

A calibração do aparelho é baseada na metodologia descrita por Silva et al. (2006) de forma a obter uma equações de calibração em diferentes camadas e para todo o perfil do solo.

As leituras foram efetuadas diariamente, sempre antes das irrigações. Portanto, foram instalados 30 tubos de acesso em PVC, com 1,0 m de comprimento de profundidade na direção perpendicular à linha de gotejo, entre duas plantas. O conteúdo médio de água no solo, em cada camada, foi calculado pela média dos valores de umidade medidos em seis tubos de acesso por tratamento. As profundidades das leituras foram de $0,10 \mathrm{~m} ; 0,20 \mathrm{~m} ; 0,30$ $\mathrm{m} ; 0,40 \mathrm{~m} ; 0,50 \mathrm{~m} ; 0,60 \mathrm{~m}$ e $0,70 \mathrm{~m}$. Contudo, no cálculo do balanço hídrico foram considerados os valores de conteúdo de água no solo, resultantes do somatório do conteúdo de água no solo nas camadas de 0 a $0,40 \mathrm{~m}$ referente ao sistema radicular da cultura.

\section{Potencial hídrico foliar}

O potencial hídrico da cultura foi determinado de modo que, o órgão a ser medido tem que ser cortado e colocado na câmara. A bomba de pressão (tipo Scholander) mede a pressão hidrostática negativa (tensão) que existe no xilema de muitas plantas segundo Scholander et 
al. (1965). Neste caso, é assumido que o $\Psi_{\mathrm{F}}$ do xilema é igual ao $\Psi_{\mathrm{F}}$ médio de todos os órgãos. Antes do corte, a coluna de água no xilema está sob tensão, quando a coluna de água é cortada a água é puxada para dentro dos capilares do xilema. Para fazer a medição, a câmara é pressurizada com gás comprimido até que a água retorne para a superfície do corte. Quando o observador notar o umedecimento da superfície do corte, deve-se parar a pressurização e anotar a pressão marcada no manômetro. Este valor negativo corresponde ao $\Psi_{\mathrm{F}}$ do órgão. Foram marcadas duas plantas por tratamento e realizado quatro repetição totalizando 8 plantas por tratamento. As leituras foram realizadas semanalmente, nos intervalo entre 6 e 7 horas da manhã (Figura 1).

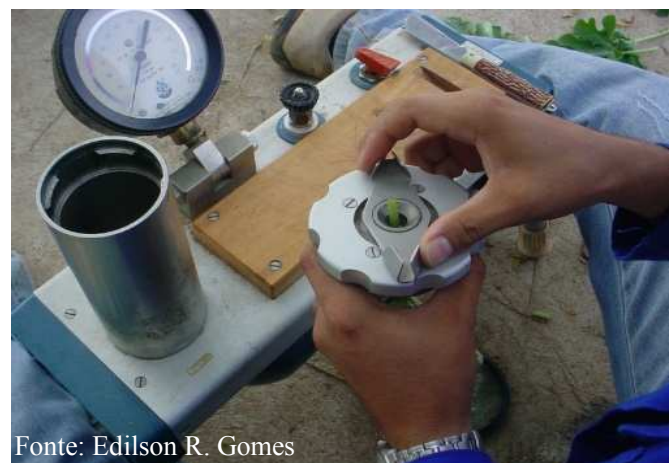

Figura 1. Determinação do potencial hídrico foliar utilizando bomba de pressão tipo Scholander.

\section{RESULTADOS E DISCUSSÃO}

Os dados climáticos foram obtidos no período de 2 meses de avaliação a partir de uma estação agrometeorológica automática instalada no Campo Experimental da Embrapa MeioNorte, em Teresina-PI. Os valores médios diários de temperatura do ar ( $T$ med), evapotranspiração de referência (ETo) estimada pelo método de Penman-Monteith, umidade relativa do ar (UR med), radiação solar (RS) e precipitação pluviométrica referentes ao período de setembro a outubro de 2010, foram utilizados para realizar o manejo de irrigação diário na cultura da melancia (Tabela 1).

Os dados de temperatura estão acima da faixa ótima para a cultura e a umidade relativa do ar abaixo. Costa e Leite (2002) relatam que o cultivo da melancia, em Petrolina-PE ocorre com a temperatura ótima variando na faixa de 23 e $28{ }^{\circ} \mathrm{C}$. A alta umidade relativa do ar favorece a incidência de doenças foliares. $\mathrm{O}$ crescimento vegetativo e o florescimento são favorecidos por fotoperíodo maiores.

Tabela 1. Dados climáticos referente ao período de cultivo da cultura da melancia (Set. a Out./2011) na região de Teresina - PI.

\begin{tabular}{ccccccc}
\hline Mês & $\begin{array}{c}\text { Período } \\
\text { (dias) }\end{array}$ & $\begin{array}{c}\text { PP } \\
\mathbf{m m}\end{array}$ & $\begin{array}{c}\text { T med } \\
{ }^{\mathbf{0}} \mathbf{C}\end{array}$ & $\begin{array}{c}\text { ETo } \\
\mathbf{m m}\end{array}$ & $\begin{array}{c}\text { UR med } \\
\mathbf{\%}\end{array}$ & $\begin{array}{c}\text { RS } \\
\mathbf{M J ~ m}^{-2}\end{array}$ \\
\hline \multirow{3}{*}{ Set } & $1-10$ & 0,3 & 28,4 & 5,2 & 54,3 & 22,4 \\
& $11-20$ & 1,4 & 29,5 & 5,7 & 54,3 & 24,1 \\
& $21-30$ & 0,0 & 30,0 & 5,7 & 54,3 & 24,3 \\
\hline \multirow{3}{*}{ Out } & $1-10$ & 0,0 & 30,3 & 5,6 & 54,3 & 23,8 \\
& $11-20$ & 0,0 & 30,4 & 5,4 & 54,2 & 22,9 \\
& $21-30$ & 24,3 & 28,6 & 4,3 & 69,6 & 19,5 \\
\hline
\end{tabular}


Valores de precipitação pluviométrica (PP), temperatura do ar - média (Tmed), evapotranspiração de referência (ETo), umidade relativa do ar - média (URmed), Radiação solar médio (RS).

\section{Lâminas de irrigação aplicadas}

As lâminas de irrigação após o transplantio se apresentaram sempre crescente até o 50 DAT em função da demanda hídrica da melancia ao longo das fases fonológicas e da evapotranspiração.

Aos 50 e 56 DAT, os valores das lâminas permaneceram quase iguais em decorrência do decréscimo da irrigação em função da fase de maturação para que ocorresse a concentração de sacarose no fruto.

No experimento, as lâminas de irrigação $1,2,3,4$ e 5 apresentaram valores de $81,15 \mathrm{~mm}$ para $\mathrm{T} 1,120,12 \mathrm{~mm}$ para T2, $160,09 \mathrm{~mm} \mathrm{~T} 3,200,67 \mathrm{~mm}$ para T4 e T5 para 232,78 $\mathrm{mm}$. Houve uma proporcionalidade entre a produtividade e a lâmina de irrigação aplicada, ou seja, a produtividade cresceu à medida que aumentaram as lâminas de irrigação. A lâmina cinco de 232,78 mm (T5) foi a que apresentou maior produtividade 42154,5 $\mathrm{kg} \mathrm{ha}^{-1}$.

Azevedo et al. (2005) estudando o efeito de níveis de irrigação na cultura da melancia cv. Micklee PVP por gotejamento, obtive uma produtividade máxima de $19,68 \mathrm{t} \mathrm{ha}^{-1}$ com a aplicação de uma lâmina de irrigação de $125 \%$ da evaporação no tanque "Classe A", a produtividade foi menor que as observadas neste trabalho.

\section{Conteúdo de água no solo}

A Figura 2 apresenta a distribuição temporal da umidade no solo ao longo do ciclo nas diferentes lâminas de irrigação aplicadas com relação as camadas. As camadas de 0,10 e 0,20 $\mathrm{m}$ apresentaram maior variação de umidade em todo ciclo em função das lâminas, a camada que mais sofre variação de umidade está situada nos primeiros $0,20 \mathrm{~m}$ de profundidade. Este fator pode está diretamente relacionado com uma maior concentração de raízes nessa cama em função de fatores externos como uma alta evapotranspiração da cultura, maior radiação solar, temperatura e umidade relativa segundo Ferreira (2012).

Pode-se observar no perfil do solo de $0,10 \mathrm{~m}$ a $0,40 \mathrm{~m}$ que a umidade do solo apresentou diferenças nos tratamentos onde T1 variou de $4 \%$ a $17 \%$, T2 de $5 \%$ a $22 \%$, T3 de $11 \%$ a $25 \%$, T4 de $15 \%$ a $27 \%$ e T5 $15 \%$ a $36 \%$ da umidade do solo.

De acordo com Reichert et al. (2003), teor de água disponível no solo tende a influência sobre a aeração, temperatura, densidade do solo e distribuição do tamanho de poros. Onde essas variáveis interfere no crescimento e funcionalidade das raízes de forma a regular o fluxo de entrada de solução para a planta, que reflete na produtividade da cultura. 


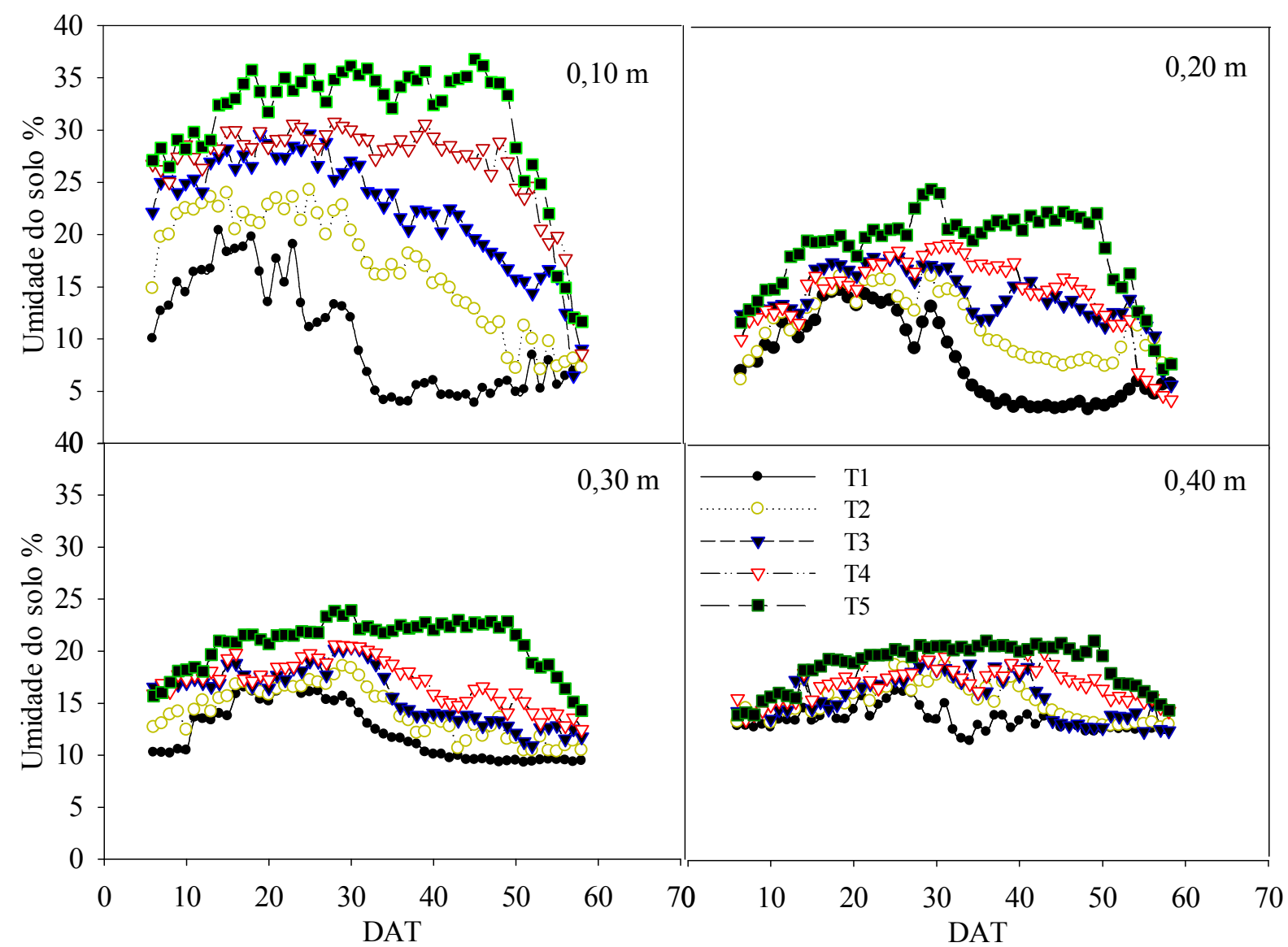

Figura 2. Distribuição da umidade do solo nas diferentes profundidades em função dos níveis de irrigação (T1 - 81,15 mm; T2- 120,12 mm; T3 - 160,09 mm; T4 - 200, 67 mm e T5 - 232,78 mm).

As camadas de $0,30 \mathrm{~m}$ e $0,40 \mathrm{~m}$ foram as que apresentaram uma umidade no solo com menor variação, que pode ser explicado pela menor concentração de raízes, consequentemente menor extração de água. Pode ser observado que a umidade foi reduzindo ao longo do ciclo, isso deve-se a um aumento da necessidade hídrica da planta, principalmente, na fase de floração e frutificação.

Pode-se verificar que os maiores valores de umidade para as lâminas de irrigação dos tratamentos cinco e quatro, expressos em todas as profundidades, as lâminas de irrigação do tratamento três apresentou-se com elevada umidade em decorrência da redução de água aplicada por parte de cada lâmina referida. Faiz e Weatherly (1978) relatam que à medida que ocorre a redução da umidade do solo, o número de raiz decresce, dificultando a reposição de água na planta.

Observa-se que os valores de umidade do solo variaram mais nas primeiras camadas em função da isolação, concentração de raízes e evaporação. A média da umidade do solo se apresentou distribuído em todo ciclo em função das lâminas, de forma a se observar que os valores estão dispostos respectivamente, $\mathrm{T} 1(\theta): 11,84 \%, \mathrm{~T} 2(\theta): 16,03 \%, \mathrm{~T} 3(\theta): 17,18 \%$, $\mathrm{T} 4(\theta): 15,91, \mathrm{~T} 5(\theta): 17,21 \%$, onde a umidade do solo de menor valor apresentou produtividade de $6351,13 \mathrm{~kg} \mathrm{ha}^{-1}$ e a maior umidade do solo de $42154,50 \mathrm{~kg} \mathrm{ha}^{-1}$. 


\section{Potencial hídrico foliar e umidade no solo}

Para todas as fases avaliadas, o potencial hídrico foliar $\left(\Psi_{\mathrm{F}}\right)$ no $\mathrm{T} 1$ apresentou-se com menor valor (Tabela 2), demonstrando que essas plantas estavam submetidas a um estresse hídrico alto, com maior ênfase na fase de crescimento (22 DAT).

Reich e Hinckley (1989) afirmam que as medidas do potencial hídrico reflete a condição hídrica tanto do solo quanto da raiz, sendo úteis para descrever o papel do estado hídrico da raiz e sua condutância hídrica em controlar o nível de perda de água pelas folhas.

Nas fases dos 22 aos 36 DAT, os valores de $\Psi_{\mathrm{F}}$ em decorrência da aplicação dos tratamentos de 2 a 5 não apresentaram diferença estatística significativa $(\mathrm{P}<0,05 \%)$, embora já tenha havido ligeira variação no conteúdo de umidade do solo. Esse procedimento era esperado, já que as diferenças em termos de lâminas de irrigação aplicadas ainda eram pequenas (Tabela 2) por ser o início do ensaio.

Tabela 2. Potencial hídrico foliar $\left(\Psi_{\mathrm{F}}\right)$ da melancieira submetida a diferentes níveis de disponibilidade de água no solo $(\theta)$, em função da aplicação de lâminas de irrigação (W) diferenciadas. Teresina, PI, 2011.

\begin{tabular}{|c|c|c|c|c|c|c|c|}
\hline DAT & W (mm) & $\Psi_{F}(\mathrm{kPa})$ & $\theta(\%)$ & $\mathbf{Q M} \Psi_{\mathbf{F}}$ & QM $\theta$ & $\mathrm{CV} \boldsymbol{\Psi}_{\mathrm{F}}$ & $\operatorname{CV} \theta(\%)$ \\
\hline \multirow{5}{*}{22} & 19,32 & $-128,75 \mathrm{a}$ & $16,78 \mathrm{a}$ & \multirow{5}{*}{$4256,25^{* *}$} & \multirow{5}{*}{$85,64^{*}$} & \multirow{5}{*}{32,18} & \multirow{5}{*}{22,23} \\
\hline & 38,67 & $-97,50 \mathrm{ab}$ & $23,52 \mathrm{ab}$ & & & & \\
\hline & 45,92 & $-80,00 \mathrm{~b}$ & $23,34 \mathrm{ab}$ & & & & \\
\hline & 57,55 & $-78,75 \mathrm{~b}$ & $20,04 \mathrm{ab}$ & & & & \\
\hline & 60,98 & $-71,25 \mathrm{~b}$ & $24,84 \mathrm{a}$ & & & & \\
\hline \multirow{5}{*}{29} & 28,22 & $-105,00 \mathrm{a}$ & $15,75 \mathrm{~b}$ & \multirow{5}{*}{$3535,00^{* *}$} & \multirow{5}{*}{$119,81^{* *}$} & \multirow{5}{*}{27,1} & \multirow{5}{*}{19,45} \\
\hline & 52,87 & $-76,25 b$ & $21,68 \mathrm{ab}$ & & & & \\
\hline & 69,02 & $-58,75 \mathrm{~b}$ & $21,81 \mathrm{ab}$ & & & & \\
\hline & 86,54 & $-56,25 \mathrm{~b}$ & $22,94 \mathrm{a}$ & & & & \\
\hline & 96,87 & $-56,25 \mathrm{~b}$ & $26,49 \mathrm{a}$ & & & & \\
\hline \multirow{5}{*}{36} & 40,91 & $-113,75 a$ & $10,02 \mathrm{c}$ & \multirow{5}{*}{$5922,50^{* *}$} & \multirow{5}{*}{$254,01^{* *}$} & \multirow{5}{*}{20,79} & \multirow{5}{*}{22,32} \\
\hline & 69,87 & $-65,00 \mathrm{~b}$ & $14,83 \mathrm{bc}$ & & & & \\
\hline & 93,00 & $-55,00 \mathrm{~b}$ & $16,77 \mathrm{~b}$ & & & & \\
\hline & 114,88 & $-55,00 \mathrm{~b}$ & $19,16 \mathrm{~b}$ & & & & \\
\hline & 130,75 & $-45,00 \mathrm{~b}$ & 25,31 a & & & & \\
\hline \multirow{5}{*}{43} & 53,91 & $-102,50 \mathrm{a}$ & $9,14 \mathrm{c}$ & \multirow{5}{*}{$5316,25^{* *}$} & \multirow{5}{*}{$311,80^{* *}$} & \multirow{5}{*}{18,67} & \multirow{5}{*}{24,89} \\
\hline & 86,82 & $-77,50 \mathrm{~b}$ & $12,53 \mathrm{bc}$ & & & & \\
\hline & 120,12 & $-57,50 \mathrm{c}$ & $17,47 \mathrm{~b}$ & & & & \\
\hline & 147,52 & $-46,25 \mathrm{~cd}$ & $16,84 \mathrm{~b}$ & & & & \\
\hline & 169,47 & $-38,75 \mathrm{~d}$ & $25,73 \mathrm{a}$ & & & & \\
\hline \multirow{5}{*}{50} & 66,91 & $-110,00 \mathrm{a}$ & $8,60 \mathrm{~b}$ & \multirow{5}{*}{$4265,00^{* *}$} & \multirow{5}{*}{$192,84^{* *}$} & \multirow{5}{*}{17,52} & \multirow{5}{*}{26,73} \\
\hline & 103,77 & $-75,00 \mathrm{~b}$ & $11,37 \mathrm{~b}$ & & & & \\
\hline & 138,32 & $-66,25 \mathrm{bc}$ & $10,63 \mathrm{~b}$ & & & & \\
\hline & 173,38 & $-65,00 \mathrm{bc}$ & $8,21 \mathrm{~b}$ & & & & \\
\hline & 201,13 & $-47,50 \mathrm{c}$ & $20,27 \mathrm{a}$ & & & & \\
\hline \multirow{5}{*}{56} & 70,11 & $-105,00$ a & $10,74 \mathrm{ab}$ & \multirow{5}{*}{$458,75^{*}$} & \multirow{5}{*}{$31,49^{* *}$} & \multirow{5}{*}{12,87} & \multirow{5}{*}{20,43} \\
\hline & 103,77 & $-93,75 a b$ & $12,22 \mathrm{a}$ & & & & \\
\hline & 138,32 & $-91,25 \mathrm{ab}$ & $13,07 \mathrm{a}$ & & & & \\
\hline & 173,38 & $-88,75 \mathrm{ab}$ & $8,24 \mathrm{~b}$ & & & & \\
\hline & 201,13 & $-85,00 \mathrm{~b}$ & $12,75 \mathrm{a}$ & & & & \\
\hline
\end{tabular}


Média seguida da mesma letra não difere estatisticamente entre si (na mesma data). DAT dias após o transplantio; $\left({ }^{*}\right)$ significativo a $1 \% ;\left({ }^{* *}\right)$ significativo a $5 \% ;\left({ }^{\mathrm{ns}}\right)$ não significativo; QM $\Psi_{\mathrm{F}}-$ Quadrado médio do potencial hídrico foliar; $\mathrm{CV} \Psi_{\mathrm{F}}$ - Coeficiente de variação no potencial hídrico foliar, já o QM $\theta$ - Quadrado médio da umidade no solo; CV $\theta$ Coeficiente de variação da umidade no solo.

Porém, aos 43 DAT, os valores de umidade do solo se mostraram bem acima da média para esse dia em decorrência do potencial hídrico foliar estar baixo e que apresentaram diferença estatística significativa $(\mathrm{P}<0,05 \%)$, proporcionada pela variação acentuada na umidade do solo, em decorrência do efeito acumulativo das lâminas de irrigação aplicadas (Tabela 2). Por se tratar da fase mais crítica da cultura ao estresse hídrico, os efeitos dessa aplicação influenciaram fortemente a produtividade final de frutos da cultura.

Já Gonsalves (2009), avaliando doses de N e K via fertirrigação e espaçamento entre plantas de melancieira com e sem sementes, observaram que o potencial hídrico decresceu aos 43 DAT para as cultivar Top Gun e a Shadow, esses resultados corroboram com o presente trabalho.

Segundo Morais (2003), os processos físiológicos e metabólicos das plantas são influenciados pela disponibilidade hídrica do solo, afetando fortemente o crescimento e a produtividade das espécies. A disponibilidade de água afeta o crescimento das plantas por controlar a abertura dos estômatos, com isso, havendo comprometimento no acúmulo de fotoassimilados, o que implica na redução da produtividade.

Dos 50 aos 56 DAT, com a suspensão da irrigação nos tratamentos 2 e 5, os valores de conteúdo de água no solo começaram a não obedecer a uma variação lógica com a aplicação das lâminas de irrigação. Com isso, os valores de $\Psi_{\mathrm{F}}$ tenderam a não ter uma variação sensível com a umidade do solo. Essa estratégia foi necessária em decorrência da proximidade da colheita e da necessidade de se elevar a concentração de açúcares nos frutos.

Ao analisar o efeito do $\Psi_{\mathrm{F}}$ sobre o rendimento da melancia, através de análise de regressão, observou-se que o modelo que melhor se ajustou aos dados foi o linear (Figura 3).

Houve uma proporcionalidade entre a produtividade e o $\Psi_{\mathrm{F}}$, ou seja, a produtividade cresceu à medida que o $\Psi_{\mathrm{F}}$ aumentou, apresentando um coeficiente de determinação $\left(\mathrm{r}^{2}\right)$ de 0,8732 , evidenciando um bom ajustamento do modelo. $\mathrm{O}$ valor médio do $\Psi_{\mathrm{F}}$ cinco $(-57,29$ $\mathrm{kPa})$ foi o que apresentou maior produtividade $42154,5 \mathrm{~kg} \mathrm{ha}^{-1}$, para o $\Psi_{\mathrm{F}}$ médio $(-110,83$ $\mathrm{kPa})$ que apresentou menor produtividade $6351,13 \mathrm{~kg} \mathrm{ha}^{-1}$, demonstrando que as plantas estavam submetidas a um maior estresse, com reflexo direto na produtividade. 


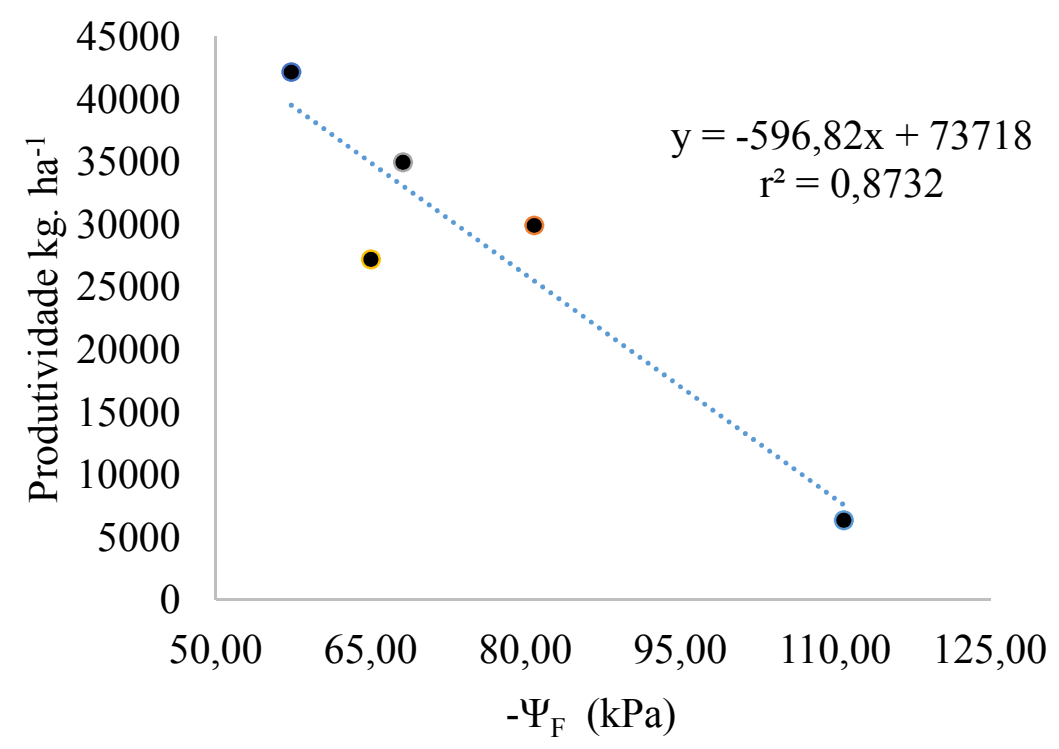

Figura 3. Desempenho da produtividade em função do potencial hídrico foliar.

\section{CONCLUSÕES}

O estado de umidade no solo interfere no potencial hídrico foliar de forma a aumentar ou reduzir a produtividade da cultura.

As fases mais sensíveis ao estresse hídrico compreendeu entre os 43 a 56 DAT (Floração e Frutificação) em que a manutenção do teor de água no solo proporciona um aumento no potencial hídrico foliar médio da melancieira, com reflexo direto na produtividade de frutos $\left(42154,50 \mathrm{~kg} \mathrm{ha}^{-1}\right)$.

Para o tratamento de menor teor de água no solo, o potencial hídrico foliar foi mínimo e subsequentemente interferindo na produtividade de frutos $\left(6351,12 \mathrm{~kg} \mathrm{ha}^{-1}\right)$.

\section{REFERÊNCIAS BIBLIOGRÁFICAS}

AGRIANUAL. Anuário da agricultura brasileira. São Paulo: FNP Consultoria e comércio. p, 400-404, 2008.

ALLEN, R, G, ET AL, Crop evapotranspiration-guidelines for computing crop water requirements, FAO Irrigation and Drenage, Roma, v, 56, p,1-300, 1998.

ANDRADE, A.R.S. et al. Estimativa da Evapotranspiração e dos Coeficientes de Cultura para Diferentes Fases de Desenvolvimento da Melancia. Revista Brasileira de Geografia Física v.6, n.5, p. 1417-1429, 2013.

AZEVEDO, B.M. et al. Efeitos de níveis de irrigação na cultura da melancia. Revista Ciência Agronômica, v.36, n.1, p.9-15, jan.-abr, 2005.

BASTOS, E. A.; ANDRADE JÚNIOR, A.S. Boletim Agrometeorológico do ano de 2006 para o município de Teresina, PI. Teresina: Embrapa Meio-Norte (Embrapa Meio-Norte. Documentos, 156), 37p, 2007. 
COSTA, N.D.; LEITE, W.M. Cultivo da melancia. Petrolina, PE: Embrapa Semi Árido. Não paginado. Apostila. Trabalho apresentado no VIII Curso Internacional de Produção de Hortaliças. Brasília, 2002.

DOORENBOS, J.; KASSAM, A. H. Efeito da água no rendimento das culturas. Campina Grande: UFPB, 221 p. (Estudos FAO: Irrigação e Drenagem, 33), 2000.

EMBRAPA. Centro Nacional de Pesquisa de Solos. Sistema brasileiro de classificação de solos. Brasília: Embrapa Informação Tecnológica; Rio de Janeiro: Embrapa Solos, 412p., 1999.

FAIZ, S. M. A.; WEATHERLY, P. E. Further investigationsinto the location and magnitude of the hydraulic resistances in the soil-plant system. New Phytologist, Cambridge, GrãBretanha, v.81, n.1, p.19-28, 1978.

FAO. (2013) Agricultural production, primary crops. Disponível em $<$ http://faostat.fao.org/site/567/ default.aspx\#ancor> Acesso em 01 de dezembro de 2013.

FERREIRA, D. F. Análise estatística por meio do SISVAR (Sistema para Análise de Variância) para Windows versão 4.0. In: REUNIÃO ANUAL DA REGIÃO BRASILEIRA DA SOCIEDADE INTERNACIONAL DE BIOMETRIA, 45. 2000, São Carlos. Anais..São Carlos: UFSCar, p. 255-258, 2000.

FERREIRA, V. M. Coeficiente de cultura e lâmina ótima de irrigação para a melancia, na microrregião de Teresina, PI. 2012. 99 f.: il. color. Tese (Doutorado em agronomiaIrrigação e Drenagem) - UNESP Câmpus de Botucatu, 2012.

GONSALVES, M. V. I. Doses de N e K aplicadas via fertirrigação e espaçamento entre plantas influenciando o desenvolvimento, a produtividade e as relações hídricas em melancieira com e sem sementes. 2009. 86 f.: il. color. Dissertação (Mestre em Agronomia Ciência do Solo) - UNESP Câmpus de Jaboticabal, 2009.

IBGE. Instituto Brasileiro de Geografia e Estatística. 2010. Indicadores conjunturais produção agrícola/agricultura. Disponível em http:// www.ibge.gov.br/. Acesso em 05 de dezembro de 2013.

KLAR, A. E. A água no sistema solo-planta-atmosfera. São Paulo. Nobel. 2.ed. p.303-383, 1984.

MORAIS, R. R. Ecofisiologia de espécies arbóreas crescidas sob condições de plantios na Amazônia Central. 158f. Tese de doutorado (Conclusão da tese de doutorado na área de Botânica) - Instituto Nacional de Pesquisas da Amazônia (INPA), Manaus-AM, 2003.

REICH, P.B.; HINCKLEY, T.M. Influence of pre-dawn water potential and soil-to-leaf hydraulic conductance on maximum daily leaf diffusive conductance in two oak species. Ecology, New York, v.3, p.719-726, 1989.

REICHERT, J. M.; REINERT, D. J.; BRAIDA, J. A. Qualidade dos solos e sustentabilidade de sistemas agrícolas. Revista Ciência \& Ambiente, v. 27, n. 2, p. 29-48, 2003. 
SCHOLANDER, P.F.; HAMMEL, H.T.; HEMMINGSEN, E.A.; \& BRADSTREET, E.D. Sap pressure in vascular plants. Science, v.148, p.339346, 1965.

SILVA, C.R.; ANDRADE JÚNIOR, A. S.; MELO, F.B.; SOUSA, A.B.; SOUZA, C.F. Calibração da sonda de capacitância Diviner $2000^{\circledR}$ em um Argissolo. XXXV CONGRESSO BRASILEIRO DE ENGENHARIA AGRICOLA, João Pessoa - PB, Resumos Expandidos, 2006.

SILVA, M. L.; QUEIROZ, M. A.; FERREIRA, M. A. J.; ARAGÃO, C. A. Variabilidade genética de acessos de melancia coletados em três regiões do estado da Bahia. Revista Caatinga, Mossoró, v. 20, n. 4, p.93-100, 2007.

SOUSA, V.F. et al. Freqüência de irrigação em meloeiro cultivado em solo arenoso. Pesquisa Agropecuária Brasileira, Brasília, v.34, n.4, p.659-664, 1999. 